\title{
PAISAGENS DA FÉ: PERSPECTIVAS PARA O TURISMO \\ CULTURAL EM CUIABÁ-MT
}

\section{LANDSCAPES OF THE FAITH: PERSPECTIVES FOR THE CULTURAL TOURISM IN CUIABÁ-MT}

\section{PAISAJES DE LA FE: PERSPECTIVAS PARA EL TURISMO CULTURAL EN CUIABÁ-MT}

\author{
Sônia Regina Romancini \\ Professora do Departamento de Geografia da Universidade Federal de Mato Grosso \\ Avenida das Palmeiras - Belevedere, Quadra 18, Lote 28 \\ 78.075-850 Jardim Imperial - Cuiabá-MT \\ romanci@terra.com.br
}

\section{Resumo}

Este artigo analisa a importância do espaço sagrado na paisagem urbana de Cuiabá-MT e suas relações com o turismo cultural. Para o desenvolvimento do trabalho foram escolhidas seis igrejas católicas e uma igreja presbiteriana, situadas no centro principal da cidade. Entre os procedimentos adotados para o desenvolvimento da pesquisa, destacou-se o levantamento bibliográfico e documental. Foram também realizadas conversas informais e entrevistas aos moradores da cidade. Concluiu-se que, além da beleza representada pelas igrejas, elas constituem um patrimônio cultural, revelando a riqueza dessa herança que, atualmente, se torna um fator de identidade para os cidadãos cuiabanos e um importante recurso turístico para a cidade.

Palavras-chave: Cuiabá-MT; igrejas; turismo cultural.

\footnotetext{
1 Artigo publicado originariamente na Revista do Instituto Histórico e Geográfico de Mato Grosso, n. 63, ano 2005. Para a presente edição procedeu-se a uma revisão.
} 


\begin{abstract}
This article analyzes the importance of the sacred space in the urban landscape of Cuiabá-MT and its relations with the cultural tourism. For the development of this research six churches had been chosen catholics and a presbiteriana church, situated in the downtown. The methodological procedures covered a bibliographical survey, an examination of artifacts and documents and the use of interviews. It was concluded that, beyond the beauty represented for the churches, them they constitute a cultural patrimony, revealing the wealth this inheritance is a fact today of identity to cuiabanos citizens and an important tourist resource for the city.
\end{abstract}

Key-Words: Cuiabá-MT; churches; cultural tourism.

\title{
Resumen
}

Este artículo analiza la importancia del espacio sagrado en el paisaje urbano de CuiabáMT y de sus relaciones con el turismo cultural. Para el desarrollo del trabajo seis de las iglesias habían sido católicos elegidos y una iglesia del presbiteriana, situada en el centro principal de la ciudad. Incorpora los procedimientos adoptados para el desarrollo de la investigación, fue distinguido el examen bibliográfico y documental. Los colloquies y las entrevistas fueran realizadas con los habitantes de la ciudad. Fue concluido que, más allá de la belleza representada para las iglesias, ellas constituyen un patrimonio cultural, divulgando la abundancia de esta herencia que, actualmente, si se convierte un factor de la identidad para los ciudadanos cuiabanos y un recurso turístico importante para la ciudad.

Palabra llave: Cuiabá-MT; iglesias; turismo cultural.

\section{Considerações Iniciais}

Este artigo apresenta uma reflexão sobre a valorização da paisagem urbana em Cuiabá, tendo como base a construção do espaço sagrado. Ao realizar estudos sobre a produção do espaço sagrado, Rosendahl (1996) afirma que o homem religioso sente necessidade de viver numa atmosfera impregnada do sagrado; por isso se elaboram técnicas de construção do sagrado.

Segundo a autora, "esse trabalho humano de consagrar um espaço, essa necessidade de construir ritualmente o espaço sagrado, nos revela que o mundo é, para o homem religioso, um mundo sagrado" (ROSENDAHL, op. cit., p. 29-30).

Em Cuiabá, o sagrado se faz presente na paisagem urbana através das igrejas que, apesar de seus nomes imponentes como, por exemplo, Catedral Basílica do Senhor Bom Jesus de Cuiabá, Igreja de Nossa Senhora do Rosário e São Benedito, Igreja de Nossa 
Senhora do Bom Despacho, elas são afetuosamente chamadas de Catedral, Rosário e Bom Despacho.

Sob esse prisma, o presente artigo discute a importância da presença das igrejas centenárias na paisagem urbana de Cuiabá, revelando a riqueza dessa herança que, hoje, se torna um fator de identidade para os cidadãos cuiabanos. Situadas no Centro Histórico da cidade e nos setores do entorno, também passíveis de preservação, a maioria destas igrejas encontra-se tombada como patrimônio histórico, seja no âmbito federal ou estadual. Assim, a delimitação de um Centro Histórico e a existência de um grande número de bens tombados, constituem um valioso patrimônio cultural e um importante recurso turístico.

No tocante ao sagrado como elemento de produção do espaço, Rosendahl (1999) afirma que as construções são moldadas pelas idéias de uma sociedade, suas formas de organização econômica e social, a distribuição de recursos e autoridade, suas atividades, crenças e valores. A autora propõe uma maneira de se olhar as cidades em relação a seu contexto cultural, estabelecendo um elo entre religião, a gênese da cidade e uma de suas funções.

Sobre a importância do patrimônio construído, Brandis e Del Rio (1998) afirmam que o marco construído ao longo do tempo e materializado no traçado e na edificação, reflete as marcas das formas culturais de se produzir a cidade. As autoras destacam que a cidade apresenta uma rica tipologia de arquiteturas e que, no momento atual, a edificação monumental é a que mais perdura por sua maior qualidade construtiva e por ser tradicionalmente a mais valorizada e conservada. Assim, as igrejas, conventos, palácios, as obras públicas, entre outras, são as que perduram na cidade atual.

Segundo Troitiño Vinuesa (1998a), as edificações herdadas do passado constituem o patrimônio cultural, que é um elemento essencial de bem-estar e de qualidade de vida das cidades que os detém. Este patrimônio, se utilizado de forma criteriosa para o turismo, oferece múltiplas perspectivas de desenvolvimento econômico e social, assim como para a criação de novos empregos. Assim, o patrimônio cultural enriquece uma sociedade no plano social e no plano cultural e seus aspectos funcionais podem participar ativamente na revitalização urbana. 
Entre os procedimentos adotados para o desenvolvimento da pesquisa, destacouse o levantamento bibliográfico e documental, que se constituiu no levantamento de bibliografia relacionada ao tema e ao conhecimento produzido em relação à área em estudo, como: livros, revistas, artigos, jornais, poesias, crônicas, relatos de viajantes, dentre outros. Foram também realizadas conversas informais e entrevistas aos moradores da cidade.

\section{Patrimônio Cultural e Recurso Turístico}

O patrimônio cultural constitui um importante recurso turístico das cidades históricas. A oferta cultural não se limita ao patrimônio arquitetônico e urbanístico, mas inclui também museus, bibliotecas, arquivos, teatros, salas de concertos, centros culturais, salas de exposições, assim como festas e eventos lúdico-culturais. Este conjunto de recursos deve aparecer em diferentes guias de recursos culturais, publicados em nível estadual e municipal.

Numa abordagem sobre a memória das cidades, Abreu (1998) salienta que, devido aos acontecimentos do século $\mathrm{XX}$, como os progressos técnicos e científicos, as guerras, a fome, entre outros, as sociedades buscam novas visões de mundo, vivendo mais o presente, desconfiando do futuro e revalorizando o que construíram em tempos passados.

Segundo Abreu, face à homogeneidade do espaço global, cada lugar procura na singularidade a sobrevivência e a individualidade, sob esse aspecto:

O passado é uma das dimensões mais importantes da singularidade. Materializado na paisagem, preservado em "instituições de memória", ou ainda vivo na cultura e no cotidiano dos lugares, não é de se estranhar, então, que seja ele que vem dando o suporte mais sólido a essa procura de diferença (ABREU, op. cit., p. 7).

O autor afirma que, na busca da "memória urbana" no Brasil, o passado está sendo revalorizado; e a preservação, recuperação e restauração do que sobrou das paisagens urbanas anteriores é um objetivo almejado pelos governos municipais.

No Brasil, as preocupações com a preservação do patrimônio histórico e artístico nacional, cujo acervo é chamado de patrimônio cultural, estão presentes na Constituição Brasileira de 1988, que, na Seção II, da cultura, Artigo 216, assegura 
"Constituem patrimônio cultural brasileiro os bens de natureza material e imaterial, tomados individualmente ou em conjunto, portadores de referência à identidade, à ação, à memória dos diferentes grupos formadores da sociedade brasileira [...]” (BRASIL, 2004, p. 111).

No âmbito federal, o Instituto do Patrimônio Histórico e Artístico Nacional (IPHAN) se responsabiliza pelo tombamento do patrimônio cultural. O tombamento é definido como o conjunto de ações realizadas pelo poder público, com o objetivo de preservar, através da aplicação de legislação específica, bens culturais de valor histórico, artístico, arquitetônico, arqueológico e ambiental, de interesse para a população, impedindo que venham a ser demolidos, destruídos ou mutilados.

Após um período de intensas transformações que atingiram o patrimônio cultural de Cuiabá, na segunda metade da década de 1980, o Conjunto Arquitetônico Urbanístico e Paisagístico da Cidade de Cuiabá foi regulamentado pelo Instituto do Patrimônio Histórico e Artístico Nacional (IPHAN), que integra a estrutura do Ministério da Cultura.

$\mathrm{Na}$ esfera estadual, a preservação do patrimônio é de responsabilidade da

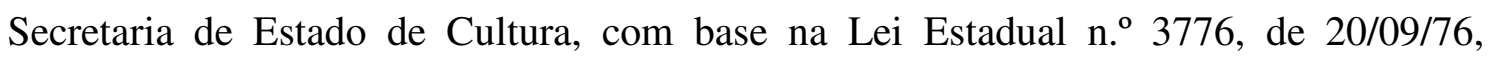
cabendo também aos municípios terem sua própria legislação para a valorização do patrimônio (ASSIS, 1997).

Entende-se que, na preservação, se busca a permanência do bem ao qual se atribui valor e/ou significado cultural. $\mathrm{O}$ ato de preservar ultrapassa a condição material do bem e alcança também seu significado histórico, seu valor imaterial, artístico, cultural, entre outros. Sob esse prisma, um bem é preservado para continuar evocando a história, a cultura e a memória de um povo para seus contemporâneos ou descendentes (CASTILHO, 1997).

Para proteger o conjunto arquitetônico urbanístico e paisagístico da cidade de Cuiabá, o IPHAN regulamenta, através de portaria, toda a sua vizinhança, que denomina de área de entorno, sistematizando critérios para a sua utilização.

Ao analisar os centros históricos, Troitiño Vinuesa (1998b) afirma que as cidades são realidades muito complexas, uma vez que em suas paisagens se refletem as características do meio natural, as heranças históricas, o jogo de forças econômicas, o progresso técnico, a capacidade criadora dos arquitetos, escultores, artesãos, as tensões 
e conflitos sociais, as formas de ser, de viver e as aspirações dos seus cidadãos. O centro histórico, além de valorizar as singularidades arquitetônicas, prima por outras dimensões como a histórica, cultural, econômica, social e simbólica.

Acerca da necessidade de proteção e conservação do patrimônio cultural, bem como sua utilização para o turismo, Troitiño Vinuesa (1995) observa que a implantação da cultura da recuperação, além das medidas de proteção e das declarações de conjuntos históricos, requer avançar no conhecimento da cidade como patrimônio e recurso cultural coletivo. $\mathrm{O}$ autor ressalta que sem um adequado entendimento da dimensão cultural do patrimônio urbanístico, será muito difícil propiciar um turismo cultural de qualidade. Para isso é preciso implementar uma política urbanística e cultural que, sendo respeitosa com os valores arquitetônicos, urbanísticos e culturais das cidades históricas, dê respostas às demandas do nosso tempo e propicie sua utilização como recurso turístico.

Ressalta-se que o turismo constitui um pilar importante da economia de muitas cidades que possuem centros históricos, contribuindo também para a conservação e a recuperação de seu patrimônio cultural. Entretanto, como a pressão do turismo pode trazer riscos para o ambiente e para a sociedade, devem ser formuladas políticas de gerenciamento desses recursos (TROITIÑO VINUESA, op. cit.).

\section{Um Olhar para as Igrejas}

A primeira igreja erigida em Cuiabá foi no Coxipó-Mirim no arraial denominado Forquilha, fundado em 1719, por Pascoal Moreira Cabral e outros bandeirantes, que levantaram uma capela dedicada a Nossa Senhora da Penha de França, na qual o padre Jerônimo Botelho celebrou a primeira missa em 1720 (MENDONÇA, 1978).

Posteriormente, em outubro de 1722, no córrego da Prainha, abaixo do outeiro onde se situa a Igreja do Rosário, o sorocabano Miguel Sutil, juntamente com dois índios e o companheiro português chamado Barbado, descobriu as minas de ouro denominadas Lavras do Sutil, em torno das quais se formou a cidade de Cuiabá. Este veio aurífero, devido à sua importância, atraiu a população da Forquilha.

As igrejas de Cuiabá se destacam como patrimônio cultural, estando algumas delas situadas em privilegiadas colinas que permitem aos transeuntes vislumbrá-las, no 
centro principal da cidade. A origem das igrejas se confunde com a da própria cidade, segundo os registros realizados.

No Plano da Vila do Cuyabá na Capitania de Mato Grosso, 1770/1780, são destacados como formadores da então vila de Cuiabá a matriz, a capela de Nossa Senhora do Bom Despacho e a capela do Rosário (REIS, 2000).

A paisagem de Cuiabá também foi descrita pelos viajantes, a exemplo de Luiz d’Alincourt que relata sua jornada a Cuiabá, realizada no ano de 1818. De acordo com seu olhar, essas eram algumas características que se sobressaíam na paisagem de Cuiabá, destacando-se os morros pontilhados por igrejas:

[...] tira o nome do rio Cuyabá, e dista da sua margem esquerda uma milha; está fundada em um vale espaçoso e alegre, que se alonga na direção nor-nordeste, ao sul-sudoeste, fechado ao nascente pelos morros do Bom Despacho, e Rosário, e ao poente pelo da Boa Morte [...] a Igreja Matriz da invocação do Sr. Bom Jesus é regular: há mais quatro templos de menores dimensões; o de N. S. do Bom Despacho, do Rosário, da Boa Morte, e o do Sr. dos Passos [...] (ALINCOURT, 1975, p. 155-6).

Em 1881, Karl Von Den Steinen, apresenta alguns aspectos interessantes da paisagem urbana de Cuiabá, que teve sua comitiva como hóspede por quase dois meses. Este pesquisador, ao notar aquela vida alegre e, de certa forma, sem grandes preocupações, elaborou uma frase para expressar a alegria do cuiabano e seu gosto pelas festas religiosas:

Não é possível que haja uma outra cidade no mundo onde se toque mais música, se dance mais, se jogue mais baralho do que aqui... É impossível, também, que em algum lugar se alteiem mais freqüentemente os estandartes da procissão e se saiba associar melhor as missas com os prazeres sociais (STEINEN, 1942, p. 68).

Steinen (op. cit., p. 84) afirma que "a vida social é o lado agradável de Cuiabá. Uma festa resgata a outra, e em toda parte se é bem acolhido". Dessa forma, ficou registrado o aspecto festivo da cidade e a alegria dos cuiabanos, características marcantes até os dias atuais. 
Atualmente, há na cidade de Cuiabá um grande número de igrejas católicas, pentecostais, centros espíritas e uma mesquita, que revelam a busca do homem pelo sagrado. Entretanto, o objetivo do presente estudo foi o de enfocar as igrejas mais antigas, materializadas na paisagem, por constituírem um espaço histórico de relevante importância para a memória coletiva da sociedade, bem como para o desenvolvimento do turismo cultural. Nessas igrejas são realizadas festas aos seus padroeiros, além de, eventualmente, serem palco para concertos, apresentações de corais, dentre outras atividades culturais.

\section{Igreja do Rosário e São Benedito}

Localizada no Centro Histórico de Cuiabá, na Praça do Rosário e tendo nas proximidades a Rua dos Bandeirantes e a Rua São Benedito, com seus casarões coloniais, a Igreja de Nossa Senhora do Rosário e São Benedito foi contemplada com o primeiro tombamento federal em Cuiabá, sendo inscrita no Livro Tombo de Belas Artes e no Livro Tombo Histórico do Instituto do Patrimônio Histórico e Artístico Nacional (IPHAN), em 4 de dezembro de 1975. A proteção abrange, além do próprio monumento, todos os equipamentos do interior da igreja, entre os quais, retábulos, imagens, alfaias e mobiliário antigo (IPHAN, 2001).

Como esta igreja, na década de 1920, recebeu uma fachada em estilo neo-gótico, com a construção de uma torre pontiaguda central, rodeada de pequenas janelas em ogiva, na década de 1970, após o tombamento federal, o IPHAN construiu uma fachada de acordo com o estilo colonial que lhe era original (IPHAN, op. cit.).

A Igreja do Rosário e São Benedito é um dos principais símbolos da cultura cuiabana, testemunho da história, espaço de reencontro entre as pessoas que se mudaram do centro principal para outros bairros, espaço da festa de São Benedito, maior expressão da religiosidade popular dos cidadãos cuiabanos. Por constituir uma permanência na paisagem, por quase três séculos, a igreja é, nos dias atuais, o principal referencial da memória da sociedade cuiabana.

Nesta igreja acontece a festa religiosa que reúne o maior número de pessoas, em Cuiabá, a festa de São Benedito, com mais de 280 anos de tradição, considerada pela comunidade como um tempo de festejos e celebrações, que se inicia com um mês de antecedência, tendo como ponto culminante o primeiro domingo do mês de julho. No 
período que antecede à festa, ocorre a visita da bandeira de São Benedito, o chá com bolo na missa de terça-feira de madrugada, os jantares nas terças à noite e o levantamento do mastro com a bandeira de São Benedito.

Os festejos se iniciam com o tríduo, que são três missas celebradas a partir das cinco horas da madrugada, de quinta-feira a sábado, sempre abordando o tema escolhido para a festa. No domingo, a missa solene começa às seis horas da manhã. Ainda como manifestações do sagrado há a reza cantada e a procissão, nesta última milhares de fiéis percorrem as ruas da cidade, louvando o santo negro e a Virgem do Rosário, por ele venerada. Ao final da procissão há queima de fogos e quermesse, marcando o encerramento da festa.

Na igreja do Rosário, ocorrem também a festa de Nossa Senhora do Carmo, realizada em um final de semana próximo ao dia 16 de agosto, e a festa de Nossa Senhora do Rosário, no primeiro final de semana do mês de outubro.

\section{Igreja de São Gonçalo}

Inicialmente, foi construída uma capela dedicada a São Gonçalo, próxima à foz do rio Coxipó, na localidade denominada de São Gonçalo Velho, atual São Gonçalo Beira Rio. Com a mudança dos rumos da cidade em direção à Prainha, em conseqüência da descoberta de ouro neste lugar, mudou também o local do porto, que foi transferido para o atual bairro do Porto, onde foi erguida uma nova capela dedicada a São Gonçalo.

Segundo Silva (1997), a capela de São Gonçalo foi erigida graças à dedicação do Juiz de Fora de Cuiabá, Dr. José Carlos Pereira, tendo sido nela celebrada a primeira missa em 15 de novembro de 1781. Posteriormente, a igreja passou por diversas modificações.

Rodrigues (MÜLLER e RODRIGUES, 1994) informa que no final do século XIX e início do século XX, o vigário padre José Solari reformou e adornou a fachada da Igreja de São Gonçalo com as imagens dos apóstolos que a encimam. Tem em sua abóbada o Cristo Redentor, estátua colocada em 1916, que mede dois metros e quarenta centímetros e está a trinta metros acima do solo.

De acordo com estudos realizados por Freitas (1997, p. 107), "a presença do magnífico templo atual possivelmente tenha obscurecido ou apagado de vez a imagem da singela capela que ainda existia no início da década de cinqüenta”. 
Em sua infância vivida no bairro do Porto, Freitas foi coroinha da Igreja de São Gonçalo e teve livre acesso às dependências anexas, como a casa antiga na continuidade do salão paroquial e outras laterais a este. Atualmente, com sua experiência de arquiteto, Freitas tece os seguintes comentários acerca das edificações que ficavam contíguas à Igreja de São Gonçalo:

Nada mais natural [...] do que reconhecer naquela casa velha, no salão paroquial com suas salas anexas laterais e em todo seu detalhamento construtivo, a primeira capela de São Gonçalo [...] Não se trata de construção provisória. Sua arquitetura, pelas características e técnica construtiva, enquadra nas tão conhecidas igrejas do passado [...] Reconheci nela tão somente uma capela singela, que guardava em planta a forma aproximada de uma cruz, lembrando o simbolismo das igrejas cristãs primitivas. Como aquelas, era desprovida de torres. Provavelmente, os sinos estariam fora, em alguma estrutura de madeira armada para esse fim (FREITAS, op. cit., p. 110).

Freitas fundamenta sua convicção de que a atual igreja não corresponde à antiga capela, baseando-se também nos relatos dos viajantes que visitaram a cidade no século XIX, como, por exemplo, Joaquim Ferreira Moutinho, que escreve em 1868: "Não temos o que admirar nesta Igreja de merecimento artístico, mas ela é vasta, simples e asseada, devendo quase tudo aos cuidados do seu pároco, que morreu de bexiga" (FREITAS, op. cit., p. 113).

Na Revista Mato Grosso, de julho de 1907, Freitas encontrou a seguinte notícia, que faz referência à capela e que, segundo ele, provavelmente neste período estaria em construção a igreja atual:

Festa de N. S. Auxiliadora na Paróquia de S. Gonçalo - Como encerramento do mês mariano solenizado pela Benção cotidiana do Santíssimo Sacramento [...] celebrou-se a 9 do mês p.p., na Capela interina da Sede Paroquial de S. Gonçalo, a simpática festividade da gloriosa Auxiliadora dos Cristãos (FREITAS, op. cit., p. 114).

Atualmente, quem transita pela Avenida XV de Novembro se depara com a bela e centenária Igreja de São Gonçalo em estilo neo-clássico, de influência toscana, que devido a sua importância como patrimônio cultural, foi tombada pela Secretaria de Estado de Cultura. Constituindo um importante espaço simbólico, especialmente para os moradores do bairro do Porto, nesta igreja são realizadas várias festas, destacando-se a 
festa de São Gonçalo, no dia 10 de janeiro. Os festejos têm início com a peregrinação da bandeira de São Gonçalo pelas principais ruas do bairro. Nos dias da festa há alvorada com queima de fogos, missa, procissão, dança de São Gonçalo, quermesse com bingo e apresentações artísticas.

Denotando a presença da comunidade na vida da igreja, no decorrer do ano acontecem ainda várias manifestações culturais e religiosas como, por exemplo, no mês de maio, dedicado à Nossa Senhora Auxiliadora, no mês de junho ao Sagrado Coração de Jesus e em outubro quando se realiza a festa de São Benedito, todas com procissão e quermesse.

\section{Igreja Senhor dos Passos}

A Igreja Senhor dos Passos, construída em taipa de pilão (terra socada), localiza-se na Rua Sete de Setembro, antiga Rua do Oratório, constituindo parte da área tombada como Centro Histórico. Segundo Freire (1997, p. 42), "o Pelourinho, a Matriz, as igrejas do Rosário e Senhor dos Passos assentam os primeiros pontos de tensão em torno dos quais a vila se estrutura e se organiza [...] Entre a igreja do Senhor dos Passos e a Matriz, paralelamente ao Prainha, abrem-se as primeiras ruas".

De acordo com Mendonça (op. cit.), a fundação da Igreja Senhor dos Passos é bastante curiosa, sendo relatada por Moutinho:

[...] José Manoel, português de nascimento, vítima de um ataque de catalepsia, foi durante ele julgado morto. Amortalhado, conduziram-no à igreja e ali, após encomendação, foi lançado à sepultura, dando-se logo começo ao enterro. Voltando a si teve forças para levantar-se, o que fez fugir a bom correr o coveiro [...] Levantado da sepultura, que era bastante profunda, saiu a custo dela, e fez então voto solene de não despir mais a mortalha, e pedir esmolas durante toda a vida, com as quais ergueria uma capela ao Senhor dos Passos. Como ainda nesse tempo havia devotos em maior abundância, o seu projeto foi facilmente levado a efeito [...] (MOUTINHO, apud MENDONÇA, op. cit., p. 21).

Posteriormente, a capela do Senhor dos Passos foi reformada e ampliada pelo bispo Dom Carlos Luiz D’Amour. Nos dias atuais, a Igreja Senhor dos Passos pertence à Paróquia da Catedral e, por ocasião da Semana Santa, é realizada a procissão da 
Fugida, com o Senhor dos Passos para a Igreja do Bom Despacho e a Procissão do Encontro, da Bom Despacho para a Catedral.

\section{Igreja de Nossa Senhora do Bom Despacho}

Quando foi construído o Seminário da Conceição, em 1858, por Dom José Antônio dos Reis, primeiro bispo de Cuiabá, já existia no Morro do Bom Despacho a pequena capela do Bom Despacho, que foi substituída por um novo templo.

A Igreja de Nossa Senhora do Bom Despacho, com estilo neo-gótico, foi idealizada pelo francês Frei Ambrósio Daydée, sendo o seu construtor o engenheiro francês Léon Joseph Louis Mousnier, que edificou vários templos na América do Sul. A pedra fundamental foi lançada em 8 de setembro de 1918, pelo bispo Dom Carlos Luís D'Amour.

A obra teve alguns períodos de interrupção. Em 1923 chegaram a Cuiabá, provenientes da Bélgica, as telhas para a cobertura e zinco para as calhas e canaletes. Em setembro de 1924 o templo foi tijolado e coberto, com a capela-mor e as duas capelas laterais terminadas. Entre 1955 e 1956, Dom Antônio Campelo de Aragão, Bispo Auxiliar de Dom Aquino Corrêa, deu continuidade ao projeto para concluir a obra (MATO GROSSO, 2004).

Para os que circulam no centro principal da cidade, a Igreja do Bom Despacho é um dos testemunhos mais significativos de sua riqueza arquitetônica. Por este motivo, em 1977, a Igreja de Nossa Senhora do Bom Despacho e o Seminário da Conceição foram tombados como patrimônio público estadual. Posteriormente, pela Lei n. ${ }^{\circ} 3265$ de 11 de janeiro de 1994, a Igreja de Nossa Senhora do Bom Despacho foi declarada como "Símbolo Cuiabano de Tradição e Cultura" do Município de Cuiabá (CUIABÁ, 2000).

Entre as atuais festividades realizadas na Igreja do Bom Despacho, destaca-se a novena e festa de Nossa Senhora do Bom Despacho, entre os dias trinta de agosto e oito de setembro, em homenagem à padroeira do templo, pois no dia oito se comemora o aniversário natalício de Nossa Senhora, uma vez que bom despacho significa bom nascimento. 


\section{Igreja Da Boa Morte}

Localizada na Praça Antônio Corrêa, na área do entorno do Centro Histórico, a Igreja de Nossa Senhora da Boa Morte é um bem tombado pela Secretaria de Estado de Cultura.

Segundo Silva (1997), esta igreja foi construída em meados do século XIX, pela sociedade formada por negros forros, pardos e escravos, denominada Irmandade Nossa Senhora da Boa Morte. A Irmandade realizava festas e procissões nos dias 14 e 15 de agosto para angariar esmolas. A igreja foi erigida canonicamente no dia 3 de maio de 1905.

Nos dias atuais, a igreja é dirigida pelos padres franciscanos. Nela é realizada a festa de Santo Antônio, no dia 13 de junho, com procissão, missa campal e quermesse. Como o dia 15 de agosto é dedicado à Nossa Senhora da Glória e da Boa Morte, no sábado mais próximo a esta data é realizada uma procissão e, no domingo, um almoço.

\section{Igreja Presbiteriana}

Situada na Rua 13 de Junho, a bela Igreja Presbiteriana, tem estilo neocolonial estadunidense e impressiona os transeuntes por sua imponência em uma rua desfigurada de suas características históricas. Embora, a parte interna da igreja tenha passado por reformas, sua fachada, com uma torre em estilo neo-gótico, teve poucos alterações.

Nos relatos do Boletim Informativo (2000) da Igreja Presbiteriana de Cuiabá, consta que o primeiro missionário chegou em Cuiabá no ano de 1891, era o Reverendo John Price, acompanhado por sua esposa, ambos enviados pela missão Aliança de Porto Alegre. Posteriormente, em 1899, chegou em Cuiabá, com sua família, o Sr. João Pedro Dias, natural da cidade do Crato-CE que "com sua visão missionária dedicou-se à evangelização e promoveu a vinda da missão Central do Brasil para Mato Grosso".

Em 1915, a Missão Presbiteriana Sul do Brasil enviou a Cuiabá o Reverendo

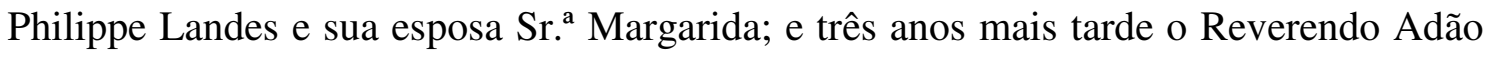
Martin e sua esposa Sr. ${ }^{\text {a }}$ Nettie Oliver. No dia 12 de outubro de 1920, a Igreja Presbiteriana de Cuiabá foi organizada, criando o seu primeiro conselho. A pedra fundamental do templo foi lançada no dia 7 de setembro de 1921. O templo foi construído com o apoio da missão e a obra foi concluída em 24 de dezembro de 1922. 
A Igreja Presbiteriana de Cuiabá é uma igreja ligada à Igreja Presbiteriana do Brasil. As datas importantes para a comunidade são lembradas com culto especial, com a presença de um pastor de renome, como no dia 12 de outubro, aniversário da igreja. Outras datas comemorativas são o Natal, o Ano Novo e a Páscoa, onde além da celebração os fiéis se confraternizam em um café da manhã.

\section{Santuário Nossa Senhora Auxiliadora}

A história do Santuário Nossa Senhora Auxiliadora está ligada à Missão Salesiana, que chegou à cidade de Cuiabá em junho de 1894, à qual o bispo Dom Carlos Luiz D’ Amour confiou a Igreja Paroquial de São Gonçalo (MENDONÇA, 1978).

A Missão Salesiana adquiriu, com o auxílio do Governo, uma chácara para abrigar os alunos internos e externos e iniciou a construção de um colégio que teve uma parte construída antes de 1897. Em outra casa funcionavam quatro oficinas, sendo elas de ferreiro, de carpinteiro, de curtidor e alfaiataria.

Cometti (s.d.) ao descrever a trajetória de Dom Aquino Corrêa, relata que um marco de sua passagem pelo Liceu Salesiano foi o lançamento da primeira pedra e o início da construção do Santuário Nossa Senhora Auxiliadora, em 24 de maio de 1912:

Apesar da pobreza em que se debatia o Liceu, que abrigava grande número de alunos internos gratuitos das Escolas Profissionais, o Padre Aquino, auxiliado pelos seus irmãos salesianos, quis erigir um templo àquela que era a "estrela de sua vida". Ao afamado arquiteto salesiano, G. Delpiano, confiara o encargo de elaborar a planta de um templo artístico, em estilo neo-gótico. E, em seus sonhos de poeta, antevia no morro fronteiriço ao Córrego da Prainha, o templo da Virgem Auxiliadora, o seu sonhado Santuário (COMETTI, op. cit., p. 93).

Segundo Cometti (op. cit., p. 94), "a fim de preparar o terreno onde seria erigido o Santuário, o Padre Malan consentiu que 24 índios bororo, dos mais robustos, viessem ao Liceu Salesiano e aí realizassem o colossal trabalho do desmonte do morro, deixando o terreno aplainado".

O Santuário de Nossa Auxiliadora foi inaugurado em 15 de abril de 1929, pertencendo à Paróquia de São Gonçalo. Além de estar aberto às celebrações da 
comunidade, tem como objetivo a formação espiritual dos educandos do Colégio Salesiano São Gonçalo.

A principal comemoração do Santuário Nossa Senhora Auxiliadora é a festa da padroeira, no dia 24 de maio, quando há procissão e missa solene.

\section{Considerações Finais}

Nos dias atuais vivenciamos uma fase de boas perspectivas no tocante à restauração e revitalização do patrimônio cultural, na cidade de Cuiabá. Com o apoio do Governo de Mato Grosso, através da Secretaria de Estado de Cultura, a Igreja do Bom Despacho foi restaurada, com recursos doados por uma empresa do sistema financeiro, e reaberta em 30 de agosto de 2004. Nessa tarde, o morro do Bom Despacho se encheu de alegria na cerimônia que reuniu autoridades civis e religiosas e centenas de fiéis que se deslumbraram com a suntuosidade e beleza da igreja.

A Igreja do Rosário foi restaurada com recursos provenientes das festas organizadas pela comunidade, das doações de fiéis e de algumas empresas que atuam em Mato Grosso, além dos recursos do IPHAN. Contou ainda com o apoio da Secretaria de Estado de Cultura e do Instituto Histórico e Geográfico de Mato Grosso. A Igreja Senhor dos Passos passou por obras de conservação.

A análise realizada permite concluir que as igrejas constituem importantes referenciais da paisagem urbana, revelando que o centro principal, bem como o bairro do Porto, são espaços ricos em história e memória, onde o novo e o moderno convivem com formas antigas, herdadas de outras gerações.

Constatou-se que, mesmo em meio a um certo abandono em que se encontra o Centro Histórico e as áreas do entorno, os cidadãos buscam as referências da cidade neste patrimônio cultural, onde se sobressaem, majestosamente, as igrejas.

As festas religiosas têm grande significado para a identidade dos cidadãos cuiabanos, elas representam o momento de reencontro com os amigos, principalmente porque com a expansão urbana, muitos moradores venderam suas casas localizadas no centro ou em suas imediações, afastando-se geograficamente das igrejas que constituem espaços de fé, de memória e de convívio social.

A alegria dos cidadãos cuiabanos é contagiante e encontra nas festas religiosas um momento de grande expressão cultural. Alvoradas, queima de fogos, celebrações 
solenes, missas de madrugada, "chá com bolo", quermesses, procissões, andores enfeitados, velas acesas e danças.

Conclui-se que, no contexto do patrimônio cultural de Cuiabá, as igrejas se destacam como importantes atrativos turísticos, tanto pela beleza e imponência, quanto pelas festas realizadas, as quais são visitadas por milhares de pessoas. Esse patrimônio, além de seu legado cultural, pode contribuir para o desenvolvimento de atividades econômicas relacionadas ao turismo.

\section{Referências Bibliográficas}

ABREU, Maurício de A. Sobre a memória das cidades. Território, Rio de Janeiro: LAGET, ano III, n.4, p. 4-26, jan./jun. 1998.

ALINCOURT, Luiz d'. Memória sobre a viagem do Porto de Santos à cidade de Cuiabá [por] Luiz d'Alincourt; prefácio de Mário Guimarães Ferri. Belo Horizonte: Itatiaia; São Paulo: Editora da Universidade de São Paulo, 1975.

ASSIS, Doralice G. Conscientizar para preservar. Secretaria de Estado de Cultura. Coordenadoria de Preservação Cultural. Cuiabá: SEC, 1997.

BOLETIM INFORMATIVO. Igreja Presbiteriana de Cuiabá. Boletim Informativo, n. 1656, out., ano XXII, Cuiabá, 2000.

BRANDIS, Dolores; DEL RÍO, Isabel. La dialéctica turismo y médio ambiente en las ciudades históricas: una propuesta interpretativa. Ería - Revista Cuatrimestral de Geografía. n. 47, Oviedo, 1998, p. 229-240.

BRASIL. Constituição da República Federativa do Brasil. São Paulo: Editora Revista dos Tribunais, 2004.

CASTILHO, Elizethe Rosa. Patrimônio histórico - uma questão de identidade. Secretaria de Estado de Cultura. Coordenadoria de Preservação Cultural. Cuiabá: SEC, 1997.

COMETTI, Pe. Pedro. Dom Aquino Corrêa: Arcebispo de Cuiabá - vida e obra. Brasília: Centro Gráfico do Senado Federal, s.d.

FREIRE, Júlio De Lamônica. Por uma poética popular da arquitetura. Cuiabá: EdUFMT, 1997.

FREITAS, Moacyr. Capela de São Gonçalo do Porto. In: Revista do Instituto Histórico e Geográfico de Mato Grosso. Tomo CXLV, Ano LXIX, p. 107-116. Cuiabá: IHGMT, 
IPHAN. Instituto do Patrimônio Histórico e Artístico Nacional. Igreja de Nossa Senhora do Rosário e São Benedito. Cuiabá: 14 SR/18 Sub-Regional do IPHAN/MT, 2001.

MATO GROSSO. Recuperação do Patrimônio Histórico - Igreja Nossa Senhora do Bom Despacho. Cuiabá, Secretaria de Estado de Cultura, 2004.

MENDONÇA, Rubens de. Igrejas \& sobrados de Cuiabá. Cuiabá: Prefeitura Municipal de Cuiabá, Secretaria Municipal de Cultura, 1978. (Cadernos cuiabanos - 7)

MÜLlER, Maria A.; RODRIGUES, Dunga. Cuiabá ao longo de 100 anos. Cuiabá, 1994.

REIS, Nestor Goulart. Imagens de vilas e cidades do Brasil Colonial. São Paulo: Editora da Universidade de São Paulo: Imprensa Oficial do Estado: Fapesp, 2000. (Uspiana - Brasil 500 Anos)

ROSENDAHL, Zeny. Espaço e religião: uma abordagem geográfica. Rio de Janeiro: UERJ, NEPEC, 1996.

ROSENDAHL, Zeny. Hierópolis: o sagrado e o urbano. Rio de Janeiro: EdUERJ, 1999.

SILVA, Paulo Pitaluga C. In: SILVA, Paulo P. C.; FREITAS, Moacyr. Gravuras cuiabanas. Cuiabá: M.E. Cardoso, 1997.

STEINEN, Karl Von Den. O Brasil Central: expedição em 1881 para a exploração do rio Xingu. Tradução de Catarina Baratz Cannabrava. São Paulo: Companhia Editora Nacional, 1942.

TROITIÑNO VINUESA, Miguel A. El turismo en las ciudades históricas. Polígonos Revista de Geografía. $n^{\circ}$ 5. León: Departamento de Geografía, Universidad de León, 1995, p.49-65.

TROITIÑO VINUESA, Miguel A. Turismo y desarrollo sostenible en ciudades históricas. Ería - Revista Cuatrimestral de Geografía. n. 47, p. 211-227. Oviedo: Departamento de Geografía, Facultad de Geografía e Historia, 1998a.

TROITIÑO VINUESA, Miguel A. Paisaje urbano y patrimônio Cultural: el centro histórico de Cuenca. Paisaje y medio ambiente. Valladolid: Universidad de Valladolid, Secretariado de Publicaciones, 1998b, p.117-135.

Recebido para publicação em maio de 2008

Aprovado para publicação em junho de 2008 